\title{
Keadilan Ekologis dan Kebijakan Elektrifikasi Perdesaan Berbasis Energi Terbarukan Lepas Jaringan di Jawa Barat
}

\author{
Cecep Aminudin ${ }^{1 *}$ \\ ${ }^{1}$ ECOTAS, Cigadung Green Land A9, Bandung 40191, Indonesia
}

\begin{tabular}{|c|c|}
\hline & Abstrak \\
\hline $\begin{array}{l}\text { Kata Kunci : } \\
\text { Keadilan } \\
\text { ekologis, } \\
\text { elektrifikasi } \\
\text { perdesaan, lepas } \\
\text { jaringan, energi } \\
\text { terbarukan, Jawa } \\
\text { Barat }\end{array}$ & $\begin{array}{l}\text { Akses masyarakat terhadap energi listrik yang berbasiskan energi terbarukan } \\
\text { merupakan salah satu bentuk manifestasi dari keadilan ekologis yang termasuk } \\
\text { keadilan sosial di dalamnya. Artikel ini bertujuan untuk menggambarkan } \\
\text { kebijakan elektrifikasi perdesaan berbasiskan energi terbarukan lepas jaringan di } \\
\text { Jawa Barat. Strategi, rencana pembangunan, rencana aksi serta mobilisasi } \\
\text { keuangan yang berkaitan dengan elektrifikasi perdesaan berbasiskan energi } \\
\text { terbarukan lepas jaringan di Jawa Barat perlu disertai dengan kebijakan tarif } \\
\text { listrik dan subsidi yang berkeadilan untuk para pengguna agar kebijakan yang } \\
\text { ada bersifat stabil, jangka panjang serta komprehensif dalam perspektif keadilan } \\
\text { ekologis. }\end{array}$ \\
\hline $\begin{array}{l}\text { Keywords: } \\
\text { Ecological } \\
\text { justice, rural } \\
\text { electrification, } \\
\text { off-grid, } \\
\text { renewable } \\
\text { energy, West } \\
\text { Java }\end{array}$ & $\begin{array}{l}\text { Abstract } \\
\text { Community access to electricity based on renewable energy is a manifestation of } \\
\text { ecological justice which include social justice. This paper aims to describe the } \\
\text { rural electrification policy based on off-grid renewable energy in West Java. } \\
\text { Strategy, development plans, action plans and financial mobilization related to } \\
\text { rural electrification based on off-grid renewable energy in West Java, need to be } \\
\text { accompanied by fair electricity tariff and subsidies policies for users to make it } \\
\text { stable, long-term and comprehensive, in ecological justice perspective.. }\end{array}$ \\
\hline
\end{tabular}

Rasio elektrifikasi yang merupakan perbandingan rumah tangga berlistrik dengan jumlah rumah tangga di Indonesia pada akhir tahun 2018 mencapai 98,30\%, naik sebesar 2,94\% dibandingkan dengan tahun $2017 \mathrm{di}$ mana rasio elektrifikasi mencapai 95,35 \% (Sekretariat Jenderal Ketenagalistrikan 2019). Peningkatan rasio elektrifikasi tersebut merupakan salah satu sasaran utama dalam penguatan ketahanan energi yang akan dicapai dalam kurun waktu 2015-2019 sebagaimana tertulis dalam Rencana Pembangunan Jangka Menengah Nasional (RPJMN) 2015-2019. Dari segi distribusi dan pemerataan, aksesibilitas sarana prasarana ketenagalistrikan masih sangat timpang, beberapa daerah masih memiliki tingkat rasio elektrifikasi di bawah 60 persen pada tahun 2013 yaitu Nusa Tenggara Timur (NTT) dan Papua, di mana masing-

\footnotetext{
*Penulis koresponden: cecep.aminudin@ecotas.org
} 
masing sebesar 57,58 persen, dan 35,55 persen (Presiden Republik Indonesia 2015).

Rasio elektrifikasi Jawa Barat (Jabar) hingga Maret 2018 telah mencapai 100\% namun dengan catatan baseline jumlah penduduk yang statis (Dinas ESDM Jawa Barat 2018). Gambar 1 berikut ini menunjukkan rasio elektrifikasi di Jabar yang terus meningkat selama 7 tahun terakhir, dari 64,309\% pada tahun 2009 menjadi $100 \%$ pada tahun 2018 .

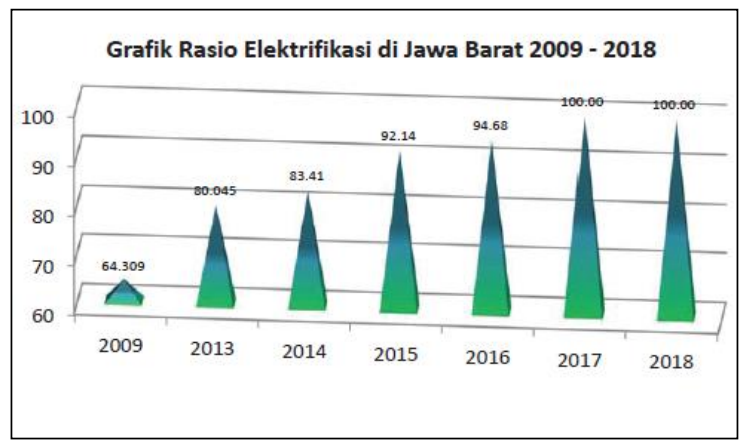

Gambar 1. Grafik Rasio Elektrifikasi di Jabar 2009 - 2018 (Dinas ESDM Jawa Barat 2018)

Kerangka kebijakan (policy framework) adalah seperangkat prinsip, tujuan jangka panjang dan komitmen yang membentuk aturan, prosedur dan pedoman dalam konteks suatu negara. Kerangka kebijakan memberikan arahan terhadap perencanaan, pengembangan dan pelaksanaan proyek elektrifikasi perdesaan secara keseluruhan. Kerangka kebijakan yang tepat adalah sebuah persyaratan bagi keberhasilan setiap proyek elektrifikasi perdesaan (Tran 2013).

Menurut dokumen ASEAN (Association of South East Asian Nations) Guideline on Offgrid Rural Electrification Approaches, sebagian besar negara-negara di ASEAN tidak memiliki kerangka kebijakan yang spesifik bagi elektrifikasi perdesaan lepas jaringan. Ketentuan mengenai elektrifikasi lepas jaringan biasanya terdapat dalam kebijakan dan rencana elektrifikasi perdesaan secara umum yang biasanya lebih fokus pada perluasan jaringan (grid extension) sebagai suatu solusi yang lebih murah (least-cost) bagi sebagian besar wilayah pedesaan. Kebijakan kunci untuk mengembangkan elektrifikasi lepas jaringan harus mencakup strategi pembangunan termasuk rencana aksi yang spesifik, kebijakan harga listrik yang transparan, serta kebijakan insentif dan mobilisasi keuangan (Tran 2013). Selain itu, struktur kelembagaan yang jelas dalam perencanaan dan pelaksanaan elektrifikasi perdesaan juga perlu melibatkan semua tingkat pemerintahan (pusat, provinsi dan daerah). Sebuah kebijakan lepas jaringan atau jaringan kecil (mini-grid) yang baik perlu bersifat stabil dan jangka panjang (stable and long-lived), jelas dan komprehensif, mudah diakses (accessible), efektif dari segi biaya (cost-effective) dan efisien, cerdas (lighthanded), sederhana, transparan dan dapat diprediksi (Franz dkk. 2014).

Daerah-daerah yang rasio elektrifikasinya rendah biasanya berada di daerah tertinggal, terpencil dan terisolasi. Oleh karena itu, diungkapkan Tran (2013), diperlukan kebijakan khusus bagi elektrifikasi perdesaan lepas jaringan mengingat karakternya yang spesifik, agar elektrifikasinya meningkat.

Pengelolaan dan pemanfaatan energi, termasuk listrik, harus mempertimbangkan setidaknya tiga aspek, yaitu pemenuhan kebutuhan ketenagalistrikan nasional dan keberlanjutannya di masa depan (energy security), keadilan energi berupa peningkatan akses atau rasio eletrifikasi dengan harga listrik yang terjangkau (energy equity), serta mempertimbangkan kelestarian lingkungan (environmental sustainability) (Hamidi dalam (Institute for Essential Services Reform 2019)).

Selain berkelanjutan, kebijakan energi terbarukan seharusnya juga berkeadilan (REN21 2019). Keadilan lingkungan atau keadilan ekologis sebagai kehidupan yang baik dan sejahtera (well-being) dari manusia dan lingkungan hidupnya di mana kehidupan manusia tergantung padanya (Gibson 2004; Shelton 2008) termasuk pemenuhan kebutuhan hidup manusia melalui pemanfaatan sumber daya alam yang terbarukan dan berkelanjutan. Keadilan ekologis mencakup keutuhan ekologis dan keadilan ekonomi serta sosial (Gibson 2004).

Artikel ini bertujuan untuk memaparkan kebijakan elektrifikasi perdesaan berbasiskan energi terbarukan lepas jaringan di Jabar. Secara spesifik, artikel ini menggambarkan strategi, rencana pembangunan, rencana aksi, kebijakan tarif listrik dan insentif serta mobilisasi keuangan yang berkaitan dengan elektrifikasi perdesaan berbasis energi terbarukan lepas jaringan di Jabar. Pokok permasalahannya adalah bagaimana kebijakan yang ada bersifat stabil, jangka panjang, komprehensif dan berkeadilan? 


\section{METODE}

Artikel ini memaparkan hasil kajian yang dilakukan terhadap data sekunder berupa sumber pustaka yang relevan dan dianalisis secara kualitatif.

\section{HASIL DAN PEMBAHASAN}

\subsection{Regulasi}

Dasar hukum elektrifikasi perdesaan dapat ditemukan dalam Pasal 4 UndangUndang Nomor 30 Tahun 2009 tentang Ketenagalistrikan (UU 30/2009) yang menyatakan bahwa untuk penyediaan tenaga listrik, pemerintah dan pemerintah daerah (Pemda) menyediakan dana untuk: (a) Kelompok masyarakat tidak mampu; (b) Pembangunan sarana penyediaan tenaga listrik di daerah yang belum berkembang; (c) Pembangunan tenaga listrik di daerah terpencil dan perbatasan; dan (d) Pembangunan listrik perdesaan (Republik Indonesia 2009).

Kebijakan peningkatan kapasitas infrastruktur pembangkit listrik EBT terdiri dari kebijakan untuk peningkatan infrastruktur yang bersifat komersial dan non-komersial (Susandy dalam (Institute for Essential Services Reform 2019)). Peningkatan kapasitas infrastruktur pembangkit listrik EBT yang bersifat komersial dengan sistem on-grid dan off-grid komunal dengan sumber dana sektor swasta (investor) diantaranya diatur dalam Peraturan Menteri (Permen) ESDM 50/2017 tentang Pemanfaatan Sumber Energi Terbarukan untuk Penyediaan Tenaga Listrik sebagaimana diubah dengan Permen ESDM 53/2018 dan Permen ESDM 38/2016 tentang Percepatan Elektrifikasi di Perdesaan Belum Berkembang, Terpencil, Perbatasan, dan Pulau Kecil Berpenduduk melalui Pelaksanaan Usaha Penyediaan Tenaga Listrik untuk Skala Kecil.

Peningkatan kapasitas infrastruktur pembangkit listrik EBT yang bersifat nonkomersial untuk masyarakat perdesaan, pulau terluar dan kawasan perbatasan dengan sistem off-grid dengan sumber dana APBN atau Dana Alokasi Khusus (DAK) diatur dalam Peraturan Presiden (Perpres) 47/2017 tentang Lampu Tenaga Surya Hemat Energi (LTSHE), Permen 33/2017 tentang Tata Cara Penyediaan LTSHE bagi Masyarakat yang Belum Mendapatkan Akses Listrik sebagaimana diubah dengan Permen ESDM 5/2018 dan Permen ESDM 39/2017 tentang Pelaksanaan Kegiatan Fisik
Pemanfaatan Energi Baru Terbarukan dengan mekanisme berdasarkan usulan Pemda sebagaimana diubah dengan Permen ESDM 12/2018.

Permen ESDM 39/2017 menggantikan kebijakan pembangunan pembangkit Energi Baru Terbarukan (EBT) yang sebelumnya diatur dalam Peraturan Menteri Energi dan Sumber Daya Mineral (ESDM) 10/2012 (Menteri Energi dan Sumber Daya Mineral 2015). Berdasarkan Permen ESDM 39/2017 juncto Permen ESDM 12/2018, pengusulan kegiatan fisik pemanfaatan Energi Baru dan Terbarukan serta Konservasi Energi (EBTKE) berupa instalasi penyediaan tenaga listrik dari EBT harus dilengkapi surat pernyataan yang berisi kesanggupan menerima dan mengelola hasil kegiatan fisik pemanfaatan EBTKE dan kesediaan melakukan dan menyediakan anggaran untuk pembinaan dan pendampingan terhadap pengelola atau penerima manfaat dari Pemda Provinsi dan Kabupaten/Kota, kementerian lainnya, atau lembaga pemerintah non kementerian (Menteri Energi Dan Sumber Daya Mineral 2017; Menteri Energi dan Sumber Daya Mineral 2018).

Kementerian ESDM memiliki kebijakan bahwa untuk daerah terpencil (isolated) yang tidak dapat dijangkau oleh jaringan listrik PLN, diarahkan untuk menggunakan potensi energi setempat seperti PLTS, Pembangkit Listrik Tenaga Bayu (PLTB) dan PLTMH (Direktorat Jenderal Ketenagalistrikan Kementerian ESDM 2013).

Sejalan dengan hal tersebut Peraturan Daerah Provinsi Jabar Nomor 21 Tahun 2014 tentang Penyelenggaraan Ketenagalistrikan (Perda 21/2014) menyatakan bahwa Pemda Provinsi mengakselerasi peningkatan rasio elektrifikasi perdesaan melalui pembangunan ketenagalistrikan yang ditujukan untuk desa. Pembangunan ketenagalistrikan untuk desa tersebut, harus terintegrasi dengan program pemanfaatan energi baru dan terbarukan (EBT) berbasis potensi energi setempat. Perda 21/2014 juga menyinggung soal pendanaan yang menyatakan pemanfaatan EBT untuk elektrifikasi perdesaan, dapat difasilitasi oleh Pemda Provinsi melalui pembiayaan yang bersumber dari Anggaran Pendapatan dan Belanja Daerah (APBD) serta sumber pembiayaan lainnya yang sah dan tidak mengikat (Provinsi Jawa Barat 2014).

Dengan demikian, setidaknya terdapat 2 (dua) kriteria elektrifikasi perdesaan lepas 
jaringan, yaitu: (a) wilayah yang tidak terjangkau listrik PLN, dan (b) memanfaatkan EBT berbasis potensi energi setempat.

\subsection{Strategi dan Rencana Aksi}

Program pemerintah yang berkaitan dengan elektrifikasi perdesaan adalah Program Listrik Perdesaan dan Program Listrik Hemat dan Murah, Pembangunan Pembangkit EBT, DAK Bidang Energi Perdesaan dan Pengembangaan Listrik Perdesaan oleh Pemda. Kebijakan program listrik perdesaan bertujuan memperluas akses listrik pada wilayah yang belum terjangkau jaringan distribusi tenaga listrik di daerah perdesaan. Program listrik hemat dan murah merupakan program penyediaan listrik pada jaringan (on grid) untuk instalasi rumah tinggal berupa penyambungan instalasi rumah tinggal untuk 3 titik lampu dan 1 stop kontak serta 3 buah lampu hemat energi (Direktorat Jenderal Ketenagalistrikan Kementerian ESDM 2013).

Program elektrifikasi perdesaan di Jabar tidak sepenuhnya merupakan elektrifikasi lepas jaringan, namun juga bisa merupakan perluasan dari jaringan Perusahaan Listrik Negara (PLN) yang sudah ada (grid extension). Modelnya adalah berupa bantuan sambungan listrik dari Pemerintah Provinsi Jabar (Pemprov Jabar) yang ditentukan oleh ketersediaan jaringan. Jaringan pasokan aliran listrik ini menjadi tangggungjawab Pemerintah Pusat melalui PLN. Sementara Pemprov Jabar membantu penyambungan dari jaringan distribusi PLN ke rumah warga, termasuk instalasinya (Pemprov Jabar 2013).

Salah satu misi pengelolaan energi Jabar adalah mengakselerasi pemanfaatan energi baru, energi terbarukan, dan konservasi energi. Salah satu prinsipnya dengan mengembangkan pemanfaatan EBT dan memprioritaskan pembangkitan energi dari energi surya baik dalam skala industri maupun masyarakat baik di perkotaan maupun perdesaan. Kegiatan pengembangan energi untuk penyediaan kapasitas pembangkit listrik antara lain mengembangkan sistem tenaga listrik kecil berbasis EBT untuk penyediaan listrik di wilayah-wilayah yang tidak terjangkau oleh perluasan jaringan (grid) serta menyempurnakan harga dan skema pembelian tenaga listrik dari pembangkit listrik berbasis EBT (Jawa Barat 2019).

\subsection{Mekanisme Pendanaan}

Mekanisme pendanaan untuk kegiatan elektrifikasi perdesaan off-grid dapat berasal dari dana pemerintah (APBN dan APBD) atau diluar dana pemerintah. Dana pemerintah dapat berupa Program Listrik Perdesaan dan Program Listrik Hemat dan Murah, Pembangunan Pembangkit Energi Baru Terbarukan (EBT), DAK Bidang Energi Perdesaan atau Pengembangan Listrik Perdesaan oleh Pemda. Dana non pemerintah dapat berupa pembangunan pembangkit dan perluasan jaringan PLN melalui Anggaran PLN atau pembangunan pembangkit Energi Baru Terbarukan oleh Koperasi, Swasta dan Lembaga Swadaya Masyarakat (LSM) (Direktorat Jenderal Ketenagalistrikan Kementerian ESDM 2013).

\subsection{Realisasi Pembangunan PLTMH dan PLTS di Jawa Barat}

Selama periode antara tahun 1995 hingga 2013 tercatat telah dibangun \pm 72 unit PLTMH yang menerangi \pm 9178 Keluarga dan \pm 5 Rumah di \pm 9 Kabupaten/Kota di Jabar. PLTMH yang dibangun memiliki daya antara \pm 2 - 4400 kilowatt (kW). Sumber dana untuk pembangunan PLTMH tersebut berasal dari APBN \pm 17 unit, APBD Provinsi \pm 29 unit, dan sumber dana lainnya \pm 26 unit. Kurang lebih tiga unit PLTMH sudah tersambung ke jaringan PLN (on grid) (Dinas ESDM Jawa Barat 2018).

Untuk PLTS, selama periode antara tahun 2001 hingga 2014 telah dibangun sebanyak \pm 137 unit dengan total keluarga yang mendapatkan listrik sejumlah \pm 7629 keluarga di \pm 14 Kabupaten/Kota di Jabar. Kapasitas PLTS yang dibangun antara $\pm 20-180$ wattpeak $(W p)$. Sumber dana berasal dari APBN sebanyak \pm 68 unit, APBD Provinsi sebanyak \pm 29 unit, APBD Kabupaten/Kota sebanyak \pm 8 unit, Kementerian Pembangunan Daerah Tertinggal (KPDT) sebanyak \pm 3 unit, dan sumber dana lainnya sebanyak \pm 29 unit (Dinas ESDM Jawa Barat 2018).

\subsection{Kebijakan Insentif}

Salah satu kebijakan insentif yang terkait dengan elektrifikasi perdesaan lepas jaringan berbasis energi terbarukan adalah Peraturan Menteri Keuangan Nomor 21/2010 yang memberikan fasilitas perpajakan dan kepabeanan untuk kegiatan pemanfaatan sumber energi terbarukan berupa fasilitas Pajak 
Penghasilan (PPh), fasilitas Pertambahan Nilai (PPN), fasilitas Bea Masuk dan fasilitas pajak ditanggung Pemerintah (Menteri Keuangan 2010).

\subsection{Kebijakan Harga Listrik dan Subsidi}

Kebijakan harga listrik dari pembangkit listrik perdesaan lepas jaringan sangat berpengaruh terhadap keberlanjutan layanan. Hal ini terkait dengan biaya untuk operasional dan pemeliharaan yang mekanismenya mungkin diserahkan pada kelompok masyarakat atau organisasi pengelola.

Layanan kelistrikan lepas jaringan biasanya mencakup suatu wilayah tertentu yang sangat kecil dalam satu desa, sehingga kebijakan mengenai tarif listriknya berada dalam kewenangan Kabupaten/Kota. Pedoman penetapan tarif tenaga listrik untuk konsumen merupakan kewenangan pemerintah pusat. Sedangkan Pemda sesuai dengan kewenangannya menetapkan tarif tenaga listrik untuk konsumen dengan persetujuan Dewan Perwakilan Rakyat Daerah berdasarkan pedoman yang ditetapkan oleh pemerintah pusat. Tarif tenaga listrik untuk konsumen berkaitan dengan wilayah usaha ketenagalistrikan di mana tarif dapat ditetapkan secara berbeda di setiap daerah dalam suatu wilayah usaha (Republik Indonesia 2009). Dengan demikian, pemerintah terlebih dahulu harus menetapkan wilayah usaha bagi suatu pengelola usaha ketenagalistrikan lepas jaringan sebelum menetapkan kebijakan tentang harga jual listrik.

Kebijakan harga listrik juga berkaitan dengan subsidi, di mana agar masyarakat miskin perdesaan dapat menikmati layanan dasar listrik, maka perlu subsidi untuk mereka agar dapat menutup gap antara kapasitas mereka untuk membayar dengan tingginya biaya untuk menyediakan listrik (Covarrubias dan Reiche 2000). Relevansi kebijakan subsidi ini terkait dengan lemahnya aspek ekonomi dalam pengelolaan pembangkit listrik lepas jaringan oleh pengelola. Misalnya yang terjadi dengan PLTMH Rimba Lestari. Aspek investasi finansial merupakan satu-satunya subdomain yang dinilai masih kurang meskipun sumber pembiayaannya operasional dan pemeliharaan berasal dari iuran bulanan komunitas. Mekanisme finansial sebagai upaya untuk membangun baru atau merevitalisasi
PLTMH lama ada bentuk tabungan yang disisihkan dari iuran bulanan. Usaha produktif dengan memanfaatkan listrik PLTMH dirintis dengan pabrik pengolahan kopi (Permadi dan Putro 2014).

Subsidi listrik, sebagai belanja negara yang dialokasikan oleh Pemerintah dalam APBN sebagai bantuan kepada konsumen atau pelanggan agar dapat menikmati listrik dengan tarif yang terjangkau (Menteri Keuangan 2019), selayaknya tidak hanya dapat dinikmati oleh pelanggan PLN agar lebih berkeadilan.

\subsection{Kebijakan Integrasi dengan Jaringan PLN}

Kebijakan penting lainnya yang perlu dipersiapkan adalah langkah integrasi pembangkit listrik yang telah dibangun pasca masuknya jaringan listrik PLN. Bagaimanapun, kebutuhan masyarakat akan kapasitas listrik yang lebih besar akan membuat masyarakat lebih memilih untuk mendapatkan listrik dari jaringan PLN dibanding suplai listrik lepas jaringan di mana kapasitas yang dihasilkannya biasanya jauh lebih rendah, hanya cukup untuk penerangan saja. Sementara kebutuhan listrik masyarakat cenderung meningkat, baik untuk usaha produktif, pendidikan, informasi atau hiburan yang berkaitan dengan peningkatan taraf hidup masyarakat.

\section{PENUTUP}

Strategi, rencana pembangunan, rencana aksi serta mobilisasi keuangan yang berkaitan dengan elektrifikasi perdesaan berbasiskan energi terbarukan lepas jaringan di Jawa Barat, penting untuk disertai dengan kebijakan tarif listrik dan subsidi yang berkeadilan untuk para pengguna. Hal tersebut agar kebijakan yang ada bersifat stabil dan jangka panjang serta komprehensif, dalam perspektif keadilan ekologis.

\section{DAFTAR PUSTAKA}

Covarrubias, Alvaro J., dan Kilian Reiche. 2000. "A case study on exclusive concessions for rural off-grid service in Argentina." Dalam Energy Services for the World's Poor: Energy and Development Report 2000, disunting oleh P. J. Brook dan S. Smith. Washington: World Bank. 
Dinas ESDM Jawa Barat. 2018. Profil Data dan Statistik Energi dan Sumber Daya Mineral Jawa Barat. Bandung: Dinas ESDM Jawa Barat.

Direktorat Jenderal Ketenagalistrikan Kementerian ESDM. 2013. "Program Listrik Perdesaan di Indonesia Kebijakan, Rencana dan Pendanaan.” http://www.iesr.or.id/Hasril_Program $\% 20$ Listrik\%20Perdesaan.pdf.

Franz, Michael, Nico Peterschmidt, Michael Rohrer, dan Bozhil Kondev. 2014. Mini-grid Policy Toolkit: Policy and Business Frameworks for Successful Mini-grid Roll-outs. Eschborn: European Union Energy Initiative Partnership Dialogue Facility (EUEI PDF).

Gibson, William E., ed. 2004. Eco-Justice the Unfinished Journey. Albany: State University of New York Press.

Institute for Essential Services Reform. 2019. Akses Energi yang Berkelanjutan untuk Masyarakat Desa: Status, Tantangan, dan Peluang. Jakarta: Institute for Essential Services Reform.

Jawa Barat. 2019. Peraturan Daerah Provinsi Jawa Barat Nomor 2 Tahun 2019 Tentang Rencana Umum Energi Daerah Provinsi Jawa Barat Tahun 2018-2050.

Menteri Energi dan Sumber Daya Mineral. 2015. Peraturan Menteri Energi dan Sumber Daya Mineral Republik Indonesia Nomor 10 Tahun 2015 Tentang Petunjuk Teknis Penggunaan Dana Alokasi Khusus Bidang Energi Perdesaan Tahun Anggaran 2015.

Menteri Energi Dan Sumber Daya Mineral. 2017. Peraturan Menteri Energi Dan Sumber Daya Mineral Nomor 39 Tahun 2017 Tentang Pelaksanaan Kegiatan Fisik Pemanfaatan Energi Baru dan Energi Terbarukan Serta Konservasi Energi.

Menteri Energi dan Sumber Daya Mineral. 2018. Peraturan Menteri Energi Dan Sumber Daya Mineral Nomor 12 Tahun 2018 tentang Perubahan Atas Peraturan Menteri Energi Dan Sumber Daya Mineral Nomor 39 Tahun 2017 Tentang Pelaksanaan Kegiatan Fisik Pemanfaatan Energi Baru dan Energi Terbarukan Serta Konservasi Energi.
Menteri Keuangan. 2010. Peraturan Menteri Keuangan Nomor 21/PMK.011/2010 tentang Pemberian Fasilitas Perpajakan dan Kepabeanan untuk Kegiatan Pemanfaatan Sumber Energi Terbarukan.

2019. Peraturan Menteri Keuangan Nomor 174/PMK.02/2019 Tentang Tata Cara Penyediaan, Penghitungan, Pembayaran, dan Pertanggungjawaban Subsidi Listrik.

Pemprov Jabar. 2013. "2014, Pemprov Jabar Bantu 70 Ribu Sambungan Listrik Desa." 2013. https://jabarprov.go.id/index.php/news /7707/2014_Pemprov_Jabar_Bantu_7 0_Ribu_Sambungan_Listrik_Desa.

Permadi, Mohamad N., dan Heru Purboyo Hidayat Putro. 2014. "Penilaian Kapasitas Komunitas Dalam Mendukung Keberlanjutan Pembangkit Listrik tenaga Mikrohidro 'Rimba Lestari' di Desa Gununghalu, Kabupaten Bandung Barat." Jurnal Perencanaan Wilayah dan Kota B SAPPK V2N1, 55-64.

Presiden Republik Indonesia. 2015. Peraturan Presiden Republik Indonesia Nomor 2 Tahun 2015 tentang Rencana Pembangunan Jangka Menengah Nasional (RPJMN) 2015-2019.

Provinsi Jawa Barat. 2014. Peraturan Daerah Provinsi Jawa Barat Nomor 21 Tahun 2014 Tentang Penyelenggaraan Ketenagalistrikan.

REN21. 2019. Renewables 2019 Global Status Report. Paris: REN21 Secretariat.

Republik Indonesia. 2009. Undang-Undang Nomor 30 Tahun 2009 tentang Ketenagalistrikan.

Sekretariat Jenderal Ketenagalistrikan. 2019. Statistik Ketenagalistrikan Tahun 2018. Jakarta: Sekretariat Jenderal Ketenagalistrikan.

Shelton, Dinah. 2008. "Making Law out of Principles of Environmental Justice." Dalam . Mexico City. http://www.iucnael.org/en/documents/ 192-dinah-shelton-making-law-out-ofprinciples-of-environmentaljustice/file.

Tran, Quang Cu. 2013. ASEAN Guideline on Off-grid Rural Electrification Approaches. Jakarta: ASEAN Centre for Energy. 